\section{La educación como praxis transformadora}

\author{
A educação como práxis \\ transformadora
}

\section{Education as a Transformational Praxis}

\section{Sandra Milena Franco Patiño*}

* Docente-investigadora del Departamento de Estudios de Familia de la Universidad de Caldas, Manizales, Colombia. Magister en Desarrollo Humano y Social del Centro Internacional de Desarrollo Humano, CINDE, y la Universidad de Manizales. Candidata a Doctora en Ciencias Sociales de la Facultad Latinoamericana de Ciencias Sociales, FLACSO, Argentina.

Correo electrónico: sandra.franco@ucaldas.edu.co
El artículo fue elaborado en el seminario "Las Ciencias Sociales en América Latina", en el marco de la formación doctoral que adelanta la autora. Es también producto de las discusiones que sostiene con el cuerpo colegiado de profesionales que orientan los procesos de desarrollo familiar en la Universidad de Caldas. La intervención directa con estos grupos familiares y comunitarios se hace desde la perspectiva de la educación para la transformación social que se desarrolla en el presente texto.

\section{Resumen}

Este artículo de reflexión se propone rescatar la tradición del pensamiento de Paulo Freire y Orlando Fals Borda, quienes postularon la educación como eje fundante para la liberación y la transformación de las sociedades, en la perspectiva de destacar la vigencia de sus postulados y, esencialmente, reivindicar el llamado que nos hacen a los profesionales de las ciencias sociales y a la sociedad en general, de actuar responsable y conscientemente en la transformación de la vida social.

\section{Palabras clave}

Educación para la libertad, Investigación Acción Participativa, educación para la emancipación, praxis educativa.

\section{Resumo}

Esse artigo de reflexão pretende retomar a tradição do pensamento de Paulo Freire y Orlando Fals Borda, os quais definiram a educação como eixo fundante para a libertação e transformação das sociedades, na perspectiva de salientar a vigência de seus postulados e, essencialmente, reivindicar o chamado que eles fazem aos profissionais das Ciências Sociais e à sociedade em geral, de agir responsável e conscientemente na transformação da vida social.

\section{Palavras chave}

Educação para a liberdade, Investigação Ação Participante, educação para a emancipação, práxis educacional.

\section{Abstract}

This reflection article proposes to rescue the Paulo Freire and Orlando Fals Borda's thinking tradition, who postulated education as a based axis for liberation and transformation of societies, in the perspective of emphasizing the validity of their postulates, and essentially, to claim a calling for the social sciences professionals, and the society in general, of acting responsibly, conscientiously, in the transformation of the social life.

\section{Key words}

Education for freedom, Participative action research, education for emancipation, educational praxis.

Fecha de recepción: 22 de marzo de 2012 Fecha de aprobación: 11 de abril de 2012

.............................................

Pedagogia y Saberes No. 36 Universidad Pedagógica Nacional Facultad de Educación. 2012, pp. 45 - 56 


\section{Introducción}

$\mathrm{L}$ as diversas, difíciles y complejas condiciones sociales, económicas, políticas y culturales que han vivido los países considerados "subdesarrollados" o en "vías de desarrollo", han constituido la motivación para que intelectuales, académicos y pensadores discutan las causas de estas condiciones materiales de vida y propongan diversos métodos de acción para enfrentarlas, superarlas o transformarlas. Por ello, es necesario volver sobre el legado de algunos de estos intelectuales latinoamericanos, quienes con su formación académica y su práctica política demostraron que el cambio, desde y con los sectores oprimidos de la sociedad, es posible.

Dos de los métodos más representativos en Latinoamérica son la Investigación Acción Participativa — en adelante IAP-, propuesto por Orlando Fals Borda en el contexto colombiano, y la Educación como práctica de libertad -comprendida como educación popular- propuesto por Paulo Freire en el contexto brasileño. Ambos pensadores, además de poseer una formación académica $\mathrm{y}$ una trayectoria intelectual $^{1}$, se distinguieron por el contenido político de sus planteamientos, orientados a romper con el orden social, económico y político que fundamenta y estructura las relaciones de la sociedad a la que pertenecían, y por concebir la educación como la estrategia fundamental para que las personas alcancen su humanización: una sociedad humanizada caracterizada por su autonomía, por el mantenimiento de una identidad nacional autóctona, ligada a los intereses y necesidades concretas de su

1 Orlando Fals Borda adelantó estudios de Maestría y Doctorado en Sociología, en la Universidad de Minnesota y Florida en Estados Unidos, respectivamente. Fue fundador de la Facultad de Sociología de la Universidad Nacional de Colombia en 1959, a la cual permaneció vinculado hasta 1970, momento en el que rompe sus vínculos académicos para emprender el compromiso político de vinculación a los grupos sociales de base, especialmente campesinos y sectores populares; no obstante, su participación y producción académica estuvo siempre presente hasta el final de sus días. Entre tanto, Paulo Freire estudió Letras y en 1959 se doctoró en Filosofía e Historia de la Educación. Fue profesor de escuela, experiencia vital que le permitió desarrollar su propuesta pedagógica. Publicó diversas obras, entre las más destacadas Pedagogía del oprimido y La educación como práctica de la libertad. población, capaz de ofrecer las condiciones para la igualdad y la justicia social.

Ante la relevancia y el reconocimiento alcanzado por las ideas de estos pensadores en la región latinoamericana ${ }^{2}$, y la influencia que ejercieron en la generación de propuestas de acción transformadora, este artículo de reflexión se propone rescatar la tradición del pensamiento de Paulo Freire y Orlando Fals Borda, quienes postularon la educación como eje fundante para la liberación y la transformación de las sociedades. El interés por relevar los contenidos políticos de este pensamiento crítico centrado en los dos autores, se fundamenta en la vigencia de sus planteamientos, en contraposición al discurso hegemónico dominante. Tal discurso dominante, sostiene que en las sociedades neoliberales no existe dominación ni opresión, y que estas han pasado a ser categorías rezagadas del pensamiento marxista o "comunista", popularizado en las décadas del sesenta y setenta del siglo $\mathrm{XX}$, que no dan cuenta de la realidad actual, y que carecen de fundamento ideológico en el contexto de desarrollo moderno y posmoderno de las nuevas sociedades.

Un análisis crítico de tal discurso evidencia que es, en sí mismo, una expresión de la ideología neoliberal para favorecer el mantenimiento del poder de las clases dirigentes que se benefician del modelo, menoscabar

2 Paulo Freire desarrolló experiencias concretas de alfabetización en el nordeste brasileño entre 1947 y 1964, momento en que fue exiliado por la dictadura militar de Goulart (Freire, [1969] 2004). Allí se dirige a Santiago de Chile para integrarse en el ICIRA (Instituto Chileno Corporación de Reforma Agraria) en el gobierno de Eduardo Frei Montalva y vincularse al partido Democracia Cristiana, donde ejerce gran influencia para emprender los procesos de reforma agraria y el Programa de Educación de Adultos en este país. Posteriormente, su legado fue difundido en toda América Latina como soporte de los procesos de educación popular que emprendieron diversas ONG y organizaciones eclesiásticas. Por su parte, el surgimiento de la IAP hace parte de una serie de preocupaciones que se venían gestando en Latinoamérica sobre el papel de la Sociología y otras disciplinas de las ciencias sociales en la comprensión de los fenómenos sociales (Guillermo Bonfil en México, Helio Jaguaribe, Álvaro Vieira Pinto y Cándido Mendes en Brasil, entre otros) pero sobre todo, en su capacidad para contribuir a revelar los mecanismos políticos que soportan los sistemas de dominación en las sociedades, desde una interpretación propia de las realidades particulares (Fals Borda, 1970). 
las posibilidades de lucha de los sectores oprimidos y evitar la sublevación de aquellos sectores que demandan una sociedad justa y democrática.

Para sustentar este planteamiento, se presenta el contexto sociohistórico en el que se desarrollan las ideas de la IAP y de la educación para la liberación, así como los postulados centrales, los lazos y las bifurcaciones entre ambos métodos. Tales postulados son el referente para instalar los desafíos éticos, cognitivos y prácticos que enfrentan los profesionales, particularmente los de las ciencias sociales, quienes por acercarse a la comprensión de los mundos de vida y significación de las personas, están llamados a intervenir protagónicamente con los grupos que trabajan, no solo para cumplir con los objetivos estipulados por los marcos institucionales, sino como profesionalesactores sociales con compromiso político y capacidad crítica respecto al sistema del que hacen parte. Más aún cuando desde el modelo económico imperante, la formación profesional se presenta como la estrategia para ascender en la escala social, más que como una oportunidad para aportar a la construcción de una sociedad que requiere del compromiso decidido de todos los actores sociales en el logro de la igualdad y la equidad económica y social.

\section{La crisis de las sociedades: contexto de emergencia de los postulados de cambio}

La historia de las naciones está marcada por cambios de diversa envergadura. Sin embargo, hay períodos de la historia que se distinguen por modificar sustancialmente las estructuras sociales, mientras que otros parecen estar en una tensa calma.

El período comprendido entre 1950 y 1970 en América Latina, estuvo constituido por revoluciones del orden social, político, económico y cultural que marcaron de manera contundente la configuración de las sociedades latinoamericanas hasta nuestros días. Las limitaciones del modelo de industrialización propuesto por la Cepal después de la segunda guerra mundial; la expansión del capitalismo; el aumento de las demandas por parte de sectores sociales articulados a Estados nacionales populares (Garretón et al, 2004), se tradujeron en amplios movimientos de lucha social. La Revolución Cubana, la imposición de regímenes dictatoriales en el Cono Sur, sumado a las situaciones particulares internas de lucha en cada país, fueron el ambiente propicio para que en la región latinoamericana se avivara un espíritu combativo, de ideales acerca de la posibilidad de revolucionar las sociedades en que se vivía.
La crisis, entendida como el resquebrajamiento del orden conocido, del declive de los paradigmas con los cuales se estructuraron las sociedades tradicionales, constituyó el referente común entre políticos, intelectuales, pensadores, organizaciones de base y diversos actores y sectores de la sociedad en este período ${ }^{3}$. El reconocimiento de la crisis sentó un precedente respecto a la necesidad de estudiar e interpretar la realidad que enfrentaba cada sociedad en su interior y en relación con los demás países; comprender los nuevos temas y tareas de la época para actuar conforme a los retos y demandas que se imponían.

En este contexto, las ideas de Paulo Freire surgen de analizar las características de la "sociedad cerrada" del Brasil ${ }^{4}$, en particular las circunstancias de miseria y explotación en las que se encontraban los campesinos del nordeste brasileño, producto de una educación alienante que los llevaba a asumir con pasividad y silencio su situación de deshumanización, un sujeto domesticado, sin espíritu crítico, acomodado ${ }^{5}$, sin cuestionamiento ni conciencia sobre su existencia. El poder de las clases dominantes sobre los campesinos y los vulnerados, condujo a Freire a postular que la transición de una sociedad cerrada a una sociedad abierta requería de la concientización de los sujetos a través de la educación o la alfabetización, que va más allá del simple aprendizaje de las letras, para verlo como un proceso de liberalización del sujeto que le permita ser más en su proyecto de humanización. El logro de un país democrático precisa, para Freire, de:

Soluciones con el pueblo y nunca sobre o simplemente para él...Y este pasaje, absolutamente indispensable para la humanización del hombre brasileño, no podría hacerse ni mediante el engaño, ni mediante el miedo, ni mediante la fuerza, sino con una educación que, por ser educación, habría de ser

3 Es amplia la literatura que designa la crisis latinoamericana desde diversas miradas: políticas, económicas, sociales. Algunos de ellos pueden consultarse en Ciencias Sociales, Ideología y realidad nacional (1970); Ideología y producción de conocimientos sociológicos en América Latina (1968); Pensamiento Crítico Latinoamericano, CLACSO; Política y sociedad entre dos épocas (2008), entre muchos otros.

4 Freire caracteriza a la sociedad cerrada del Brasil como aquella "sociedad 'refleja', a la cual correspondía una tarea alienada y alienante de sus élites, distanciadas del pueblo, superpuestas a su realidad. Pueblo... inexistente en cuanto a su capacidad de decidir a quién correspondía una mínima tarea, siempre oprimido, ser guiado por los apetitos de la élite que estaba sobre él" (Freire, [1969]2004, p. 37).

5 En Freire el concepto de "acomodación" se refiere a la pérdida de la capacidad de optar, de decidir, de crítica para transformar la realidad; ante esta pérdida, el sujeto se acomoda a prescripciones o mandatos que no le son propios. 
valiente, ofreciendo al pueblo la reflexión sobre sí mismo, sobre su tiempo, sobre sus responsabilidades, sobre su papel en la nueva cultura de la época de transición. (Freire, [1969] 2004, p.51)

Las ideas de Orlando Fals Borda, por su parte, surgen en medio del debate existente al interior de las disciplinas de las ciencias sociales - particularmente la Sociología- respecto al carácter de cientificidad que otorga la neutralidad valorativa y la independencia del investigador respecto a la realidad que conoce, y a la capacidad de la Sociología para revelar los mecanismos políticos que soportan la crisis, la racionalidad de los procesos de cambio y la comprensión de las realidades que vive el pueblo que las sufre. Su crítica se orientó a las teorías y los métodos asumidos por las comunidades académicas de las instituciones de educación superior en Colombia, quienes extrapolaron modelos europeos y estadounidenses (racionalismo cartesiano, positivismo, materialismo y funcionalismo parsoniano) para la enseñanza, la investigación científica y pedagógica y la producción y sistematización del conocimiento científico; modelos que, aunque importantes en varios sentidos, resultaban insuficientes y restrictivos para entender las realidades propias del 'trópico' ${ }^{6}$ y crear un pensamiento autónomo sobre la problemática latinoamericana (Cfr. Fals Borda, 1970, pp. 61-64).

Estas preocupaciones respecto al quehacer científico, le condujeron a deconstruir y reconstruir la práctica investigativa, en una propuesta que

articula la teoría con la acción, una sociología comprometida ${ }^{7}$ con el pueblo, con sus intereses y sus necesidades de emancipación, un conocimiento que vinculara el saber del pueblo con el saber intelectual, en la comprensión de los problemas concretos del país y la región:

Las normas generales que mejor podrían guiar el trabajo científico en épocas de crisis parecen ser aquellas que resultan de la experiencia misma de la aplicación del método a los procesos sociales [...] La mejor manera de saber si se va por la mejor dirección -y saber, por lo mismo, si se está siendo objetivo o no- es la de producir hechos y hacer que las ideas se traduzcan a la práctica [...] que la teoría se deje guiar por la realidad para que pueda enriquecerse. (Fals Borda, 1970, p. 70)

\section{Educación para la liberación: el fundamento de la educación popular}

Durante la primera mitad del siglo XX, la sociedad brasileña vivía una transformación de la estructura económica y social que demandaba respuestas para enfrentar la transición entre la vieja sociedad cerrada y la nueva sociedad abierta. Una de ellas fue planteada en el campo de la pedagogía por Paulo Freire, al considerar las circunstancias sociohistóricas de la población (que podían asimilarse a otros contextos latinoamericanos), los problemas del desarrollo económico y la necesidad de inserción crítica del hombre $^{8}$ brasileño en la democratización que enfrentaba (Freire, [1969] 2004, p.80).

Freire analiza críticamente el "analfabetismo" que enfrentaba la gran mayoría de la sociedad brasileña, como expresión de una estructura social histórica particular en la que priman los intereses de las clases dominantes y de las oligarquías instauradas en el poder, quienes, a través del sistema educativo, reproducen las condiciones de dominación y deshumanización de las personas, único medio para mantener su statu quo y perpetuar su carácter opresor. El autor señala que esta forma de organización de la sociedad es histórica, en tanto sus condiciones materiales y objetivas son susceptibles de ser modificadas, en la medida que los hombres reflexionen críticamente sobre su situación
6 Para el autor, el entorno natural, ambiental, geográfico, social y cultural constituye un proceso vital de la realidad que viven los pueblos, por ello el trópico refiere a la condiciones naturales y sociales que otorga una particular identidad a los habitantes de la zona amazónica, andina y chocoana que conforma el territorio colombiano.

7 En esta misma línea de ideas se destacan los aportes de Luis A. Costa Pinto y Florestán Fernández en Brasil.
8 En su obra, Paulo Freire refiere al hombre en tanto concepto general para referirse a lo humano sin entrar en distinciones de género, pero que supone la inclusión de hombres y mujeres de diversa edad, etnia y clase que se encontraran alienados por el sistema opresor y requirieran emanciparse. Muchos de sus análisis se fundan en las observaciones de proletarios urbanos, campesinos, hombres de clase media con quienes adelantó procesos educativos. 
de opresión, entiendan conscientemente la realidad del mundo en el que existen y asuman el compromiso histórico con la lucha organizada para su liberación. Para Freire, "la alfabetización, y por ende toda la tarea de educar, sólo será auténticamente humanista en la medida que procure la integración del individuo a su realidad nacional, en la medida en que pueda crear en el educando un proceso de recreación, de búsqueda, de independencia y, a la vez, de solidaridad" (Freire, [1969] 2004, p. 14).

El educador brasileño plantea "la educación como práctica para la libertad", en contraposición a la "educación bancaria" como instrumento de la ideología de la opresión. La educación liberadora desarrolla la conciencia crítica del sujeto, producto de la reflexión-acción del mundo natural y social del que forma parte, para integrarse ${ }^{9}$ así en su contexto y asumir en el diálogo constante y el encuentro con los otros, la acción transformadora que incida sobre su realidad, la instauración de una sociedad diferente que posibilite la búsqueda del ser más (Cfr.

Freire, [1970] 2002, p. 45).

El ser más es la lucha constante de los oprimidos por superar la situación opresora; una lucha de contradicción y dialéctica. Los oprimidos, al estar inmersos en el engranaje de la estructura de dominación, sienten la desesperanza y el temor a la libertad que no han poseído, viven la represión que ocurre en su búsqueda y temen las amenazas que esto significa; a su vez, la condición de opresión se constituye en el impulso del deseo de liberación y superación de las cadenas a las que han estado sometidos. Para Freire, esta situación es dialéctica en tanto los oprimidos, en su búsqueda de libertad, viven la experiencia de opresores en sí mismos, al ser este el referente de su experiencia, y al no saber cómo llenar el vacío que ha dejado la expulsión de la sombra opresora, tienden a reproducir el carácter de opresores. La lucha se da entre ser ellos mismos o ser duales: expulsar o no al opresor desde 'dentro' de sí, desalienarse o mantenerse alienados, seguir prescripciones o

9 La integración es la existencia del hombre en el mundo y con el mundo; trascender, discernir, dialogar, implica que tanto la visión de sí mismo como la de mundo no pueden hacerse absolutas, esta se perfecciona en la medida que la conciencia se torna crítica (Freire [1969] 2004, p. 31). tener opciones: Por esto, "la liberación es un parto [...] el hombre que nace de él es un hombre nuevo, hombre que sólo es viable en y por la superación de la contradicción opresores-oprimidos que, en última instancia, es la liberación de todos" (Freire, [1970] 2002, p. 47).

Para que la educación sea una práctica de la libertad, se requiere reconocer la bidireccionalidad del aprendizaje entre educador-educando, ofrecer las condiciones materiales objetivas y subjetivas para que los seres humanos avancen en la toma de conciencia para sí y que el proyecto de humanización, de creatividad, de imaginación, de acción transformadora sea la base fundante del sujeto histórico en todas las sociedades.

Pese a que los hombres disponen de la capacidad para reflexionar sobre su mundo y su existencia, su liberación es un proceso permanente de toma de conciencia que no ocurre per se; requiere de un trabajo educativo-crítico que favorezca y promueva la reflexión y la acción sobre la vida propia y el mundo en que ella se desarrolla; que amplíe la comprensión de los condicionamientos históricos y culturales que el sujeto afronta en lo individual, familiar y social, para que pueda reconocerse como sujeto histórico, con opciones, con responsabilidades y compromisos frente a su existencia en el mundo y con el mundo, del cual forma parte.

El proceso de toma de conciencia avanza - siguiendo a Freire- de una transitividad ingenua a una transitividad crítica. La transitividad se entiende como la ampliación del poder de comprensión del mundo, de los retos, demandas y exigencias provenientes del exterior relativas al papel político y social que se espera cumplan los hombres en la sociedad. Cuando los sujetos aumentan su capacidad de diálogo con otros hombres y con la vida social, logran superar la preocupación por resolver aquellos aspectos individuales de supervivencia y el encerramiento al que están sometidos con sus preocupaciones inmediatas, al develar que las raíces de su condición se encuentran ancladas en la organización social fundante y que, por lo tanto, ellos, como seres en el mundo, disponen de capacidad para actuar críticamente en él. Esta transitividad, en tanto proceso, se cualifica y perfecciona de estados menores a mayores de conciencia - aunque no linealmente-. 
Así, de una conciencia 'ingenua' donde el discernimiento, la argumentación, la explicación de los problemas es limitada, mítica, polémica, se evoluciona hacia una conciencia 'crítica' que profundiza en la interpretación de los problemas de manera integral, con agudeza, con fundamentación y soporte de racionalidad, emocionalidad, argumentos, decisiones y actos: "La transitividad crítica implica que el hombre comprenda su posición dentro del contexto. Implica su injerencia, su integración, la representación objetiva de la realidad. De ahí que la concienciación sea desarrollo de esa toma de conciencia" (Freire, [1969] 2004, p. 54).

Como puede apreciarse, los planteamientos de la educación como práctica liberadora constituyen, por una parte, un nuevo paradigma que, anclado en la historia, la dialéctica y la praxis transformadora, propone una nueva manera de comprender las condiciones históricas, económicas y políticas de las sociedades y el papel político de los hombres como hacedores de realidad; por otra parte, constituye una propuesta política de cambio social, cuyo propósito es la transformación radical y estructural de las bases de la opresión y la dominación de los pueblos. Este nuevo paradigma de comprensión de la realidad social con intencionalidad política de cambio, dio lugar en América Latina a una corriente educativa comprometida con los proyectos y los movimientos de liberación social y cultural que alcanzaron gran auge en la década del 60; nace así la educación popular ${ }^{10}$.

Se trataba de entender el contenido político de la educación y su potencialidad para el cambio social, así como la pedagogización de la política, en la que los sectores populares tienen un lugar protagónico. En el primer caso, se reconoce que la educación no es neutra. En regímenes de dominación como los que han caracterizado a los países latinoamericanos,

10 Gran parte del pensamiento del educador brasileño y de su teoría de la acción dialógica, ampliamente desarrollada en la pedagogía del oprimido (2002a), fundamentan la educación popular como enfoque alternativo a la educación tradicional y las teorías educativas dialógicas. No obstante, la propuesta de Freire no se circunscribe al ámbito de la educación formal institucional: por el contrario, su postura es entender la educación como posibilidad de humanización en la que todo acto de la vida cotidiana constituye fuente de saber y conocimiento. ha sido instrumento de opresión; en regímenes democráticos la educación es instrumento de toma de conciencia de la realidad injusta y de la necesidad de transformarla. Con base en ello se plantea, como alternativa al modelo educativo tradicional escolarizado, una educación para la vida, cuyo punto de partida es la problematización del contexto y de las situaciones que viven los sectores populares, al ser quienes mayoritariamente han vivido la opresión de las élites; el reconocimiento de los saberes que ellos poseen gracias a su experiencia cotidiana, al hacer concreto en que llevan a cabo su vida social; y la confianza en que en el diálogo - como método fundante de la práctica de libertad- permanente entre educadores y educandos se hace efectivo el proyecto de humanización y la creación de una realidad social en la que tiene cabida el sentir y los deseos del pueblo (Cfr. Freire, 2002a, p. 70).

Si a la educación le subyace un contenido y una intencionalidad política, es necesario a su vez pedagogizar la práctica política; es decir, entender que la construcción de una nueva sociedad es un derecho fundamental de todos los seres humanos y no solo de aquellos que en razón de su poder económico, científico o político (polity), se han otorgado la capacidad para dirigir y orientar la vida de otros. Pedagogizar la práctica política requiere de por lo menos dos momentos: en primer lugar, que los sectores marginados y oprimidos reconozcan las causas y el carácter de la opresión, así como las posibilidades de acción y de transformación de ellas; en segundo lugar, $y$, una vez se avanza en la modificación de las prácticas opresoras, la pedagogía del oprimido pasa a ser la pedagogía de la liberación, en la medida que los oprimidos logran expulsar de sí el opresor que llevan dentro y que pueden empezar a explorar

la construcción de una sociedad nueva, emergente, progresista. De esta forma, la organización de los sectores populares, la lucha compartida, la movilización, la resistencia, se convierten en estrategias de práctica política que además de combatir el régimen opresor, posibilitan encontrar alternativas de acción posible: "La praxis es posible a través de la reflexión y la acción (dimensiones fundantes de la palabra) que inciden sobre las estructuras que deben transformarse" (Freire, 2002a, p. 111). 
Ahora bien, podría decirse que estos planteamientos tienen sentido como principios teleológicos, axiológicos y éticos, pero que en modelos económicos como el neoliberalismo actual las posibilidades de llevar a cabo esta propuesta no parece tener asidero. Y aquí, Freire nos recuerda nuevamente que la hegemonía del poder que construye el capitalismo, se basa en la desesperanza generalizada y en la promoción del individualismo, para evitar el caos y la irrupción al orden que daría lugar el levantamiento de los sectores populares. En la Pedagogía de la esperanza, este educador nos recuerda gran parte de los movimientos sociales que han tenido lugar en diversas épocas y lugares del mundo, como un grito que clama por ser oído, por encontrar eco entre todos aquellos que padecen la inequidad, la desigualdad y la opresión en el mundo:

\section{Sin poder negar la desesperanza como algo concreto y sin desconocer las razones históricas, eco- nómicas y sociales que la explican, no entiendo la existencia hu- mana y la necesaria lucha por mejorarla sin la es- peranza y sin el sueño. La esperanza es una necesidad ontológica; la desesperanza es es- peranza que habiendo perdido su dirección, se convierte en distorsión de la necesidad ontológica. (Freire, 2002b, p. 24) \\ Método de la Investigación Acción Participativa o IAP}

Similar a lo ocurrido en Brasil, durante la primera mitad del siglo XX en Colombia se desplegó la modernización política, económica y social —expresada como impulso a la industria, la urbanización, la garantía de derechos laborales, la infraestructura, entre otrosacompañada de una violencia política que permanece hasta la actualidad. Esta violencia socio-política, que ha caracterizado al país en su desarrollo histórico, sumada a las crisis del desarrollo económico, marca particularidades respecto a las posiciones y las prácticas que han asumido diversos sectores sociales para salir de tal situación. En particular, las instituciones universitarias, como centros especializados del saber y el conocimiento científico, se distinguieron por realizar investigaciones que desentrañaran el origen, las causas, las representaciones y las consecuencias políticas, sociales, culturales y simbólicas de la violencia en Colombia, o de diversas problemáticas de la realidad colombiana, distanciadas, en gran medida, de la vinculación y la acción concreta con los grupos sociales en estudio.

Esta situación es fuertemente criticada por parte de algunos miembros de la comunidad académica - principalmente por Orlando Fals Borda ${ }^{11}$ - y por distintos actores sociales, quienes cuestionaban la primacía otorgada a la ciencia, al conocimiento y a la razón, en la separación tajante entre teoría y práctica y entre sujetos/objetos de investigación y el investigador. El interés se centró entonces en establecer las reglas de una ciencia que, además de rigurosa y pertinente, fijara su atención en el conocimiento de las gentes del común.

Con ello, se puso en entredicho la visión clásica de ciencia como leyes confirmadas y verdades absolutas, la "racionalidad" como forma de explicar y controlar los hechos sociales, y la "objetividad" como criterio de cientificidad y generalización.

En contraposición, se postula que

la ciencia se construye en la interacción social que establecen los investigadores entre ellos y con el mundo que conocen, luego, la ciencia está sujeta a interpretaciones, reinterpretaciones, revisión, enriquecimiento y creación.

Pero no solo los investigadores conocen el mundo y construyen explicaciones sobre él, también la gente del común - comunidades indígenas, negras, campesinos, obreros - tiene un saber generado en la experiencia de la vida cotidiana, es decir, existen otros tipos de conocimiento aunque no sean suficientemente conocidos ni valorados en el ámbito académico y científico. La articulación entre conocimiento popular y conocimiento científico significó reconocer a los sujetos de investigación como personas con capacidad para

11 Aunque Fals Borda aparece como uno de los actores principales de estos cuestionamientos, sus planteamientos corresponden a un paradigma que emergía en el contexto colombiano y latinoamericano, centrado en los postulados de la ideología socialista, la teología de la liberación y el nacionalismo revolucionario, que planteaba que el cambio profundo y radical de la realidad política y social en las sociedades radica en la acción concreta con los grupos de base, quienes han estado por fuera del poder. Al respecto, se destaca el estrecho vínculo con Camilo Torres, con quien compartió gran parte del trabajo académico en la reciente Facultad de Sociología, el grupo Golconda, la ONG llamada la Rosca de la Investigación y Acción Social a través de la cual se debatieron, construyeron y difundieron ampliamente los postulados de la IAP. 
pensar, sentir y actuar. Superar la instrumentación de ellos como "cosas" de las que se disponen, según los fines del investigador, para integrarlos en un sistema de conocimiento del que forman parte, bajo relaciones de cooperación (y no de dominación) democrática en la perspectiva de transformar las prácticas, las conductas y los pensamientos favorables al desarrollo humano.

Este giro, en la manera como se conciben los sujetos de la investigación por parte de los investigadores, replantea la práctica de investigación: la visión de sujeto, los roles asignados y asumidos, los intereses, las finalidades y los productos investigativos. Fundamentalmente, establece formas de relación de mayor igualdad y horizontalidad entre investigados e investigadores, al reconocerles a los sujetos participantes de la investigación su capacidad de decisión y actuación, para transformarse internamente y transformar el entorno del cual hacen parte.

Estas consideraciones llevan implícitos un compromiso ético respecto al propósito y el aporte del conocimiento al proyecto de humanización. En ese sentido, tan importante es el conocimiento técnico-científico, como el conocimiento para enfrentar y resolver hechos cotidianos que vulneran los derechos esenciales de las personas, las condiciones que las marginan y las excluyen del desarrollo humano y social.

Este nuevo paradigma reevalúa la práctica científica que se sustenta, como hasta ahora, en intereses individuales de los investigadores para hacer trayectoria académica, obtener reconocimiento social y entrar en los círculos de consagración, o en intereses institucionales que se acomodan a los requerimientos de las esferas de poder que dominan los temas a investigar, su financiamiento y las características que esta asume. En pocos casos, los intereses de los sujetos participantes de la investigación constituyen el eje fundante del conocimiento. Encarar esta situación, significó descolonizar aquellas actitudes reaccionarias que soportaron la concepción y los comportamientos respecto al conocimiento, y encontrar formas alternativas de hacer ciencia, considerando la praxis y el quehacer directo con los grupos objeto/sujeto de investigación.

Con base en estos planteamientos, Fals Borda (1970) señala la necesidad de que la Sociología y, en general, las ciencias sociales, se comprometan con el contexto de crisis que viven las sociedades, para obtener una transformación significativa del pueblo que permita sortear la crisis decisivamente, creando una sociedad mejor a la existente. En tal sentido, son los intelectuales, los científicos y los profesionales los llamados a asumir el compromiso (engagement), entendido como "la acción o la actitud del intelectual que, al tomar conciencia de su pertenencia a la sociedad y al mundo de su tiempo, renuncia a una posición de simple espectador y coloca su pensamiento o su arte al servicio de una causa [...] El compromiso con esta causa de la transformación fundamental es la acción válida, el engagement consecuente" (Cfr. Fals Borda, 1970, p. 78).

Este compromiso-acción será el que posibilite la articulación teoría-práctica, donde converja la conciencia de los problemas que se estudian y analizan con los conceptos y desarrollos teóricos aplicables a dichos problemas. En resumen, la Investigación Acción Participación (IAP) designa una práctica de investigación que conjuga teoría y praxis, articulada a realidades concretas de los sujetos o grupos sociales más vulnerados, quienes son actores protagónicos en el proceso de entender, explicar, comprender y transformar su realidad y producir conocimiento sobre ella. Es el compromiso decidido con un conocimiento que sirva para mejorar la práctica, tal como lo enfatizaron los educadores de la concientización ${ }^{12}$.

\section{La educación para la concientización: lazos y bifurcaciones}

La idea de lazos y bifurcaciones refiere a elementos convergentes y diferenciales presentes en estos dos autores. Como lazos a través de los cuales se teje una red que fundamenta la concepción de educación para la concientización, se pueden establecer —además del compromiso político y su aporte al pensamiento crítico latinoamericano- los siguientes:

12 En diversos escritos Orlando Fals Borda indica que sus ideas se fundamentan en los planteamientos de pensadores latinoamericanos inscritos en esta misma corriente de pensamiento: José Carlos Mariátegui, Ignacio Torres Giraldo, Luis A. Costa Pinto, Paulo Freire, entre otros (Fals Borda, 1999, p.74). 
- La importancia concedida a la historia, no solo como referencia del pasado sino como condiciones sociales y políticas concretas en tiempos y espacios específicos, que dan lugar a sujetos ubicados en contextos que les demandan capacidad para actuar con responsabilidad colectiva en la construcción de sociedad.

- La línea liberadora que persiguen, al coincidir en que el ordenamiento de las sociedades y las estructuras de poder en que se han soportado las relaciones sociales han generado desigualdad e injusticia social a la gran mayoría de la población. Superar estas condiciones será posible en la medida que la educación contribuya a la toma de conciencia de los sujetos para movilizar su acción y compromiso con las causas colectivas, en que los actores asuman su poder de cambio y que los educadores se comprometan con la transformación social.

- La interrelación dialéctica entre lo micro y lo macro social en diversas escalas, como elementos constitutivos de un todo: el mundo de los dominados en relación con la clase dominante; las condiciones sociales, políticas, económicas, ambientales y culturales de una sociedad, estructuran y organizan la vida individual, familiar y comunitaria de la población quien a su vez, en las relaciones en estos ámbitos, configura formas de relación e interacción con la sociedad; la particularidad de la naturaleza sociohistórica de cada nación y sus conexiones con las demás naciones.

- La concepción de sujetos y no objetos del acto educativo y del proceso de liberación. Se reconoce la indeterminación y la perfectibilidad del proyecto de humanización que debe seguir siendo el horizonte hacia el cual avancen las sociedades, para ofrecer nuevas oportunidades favorables a todas y todos los habitantes del planeta.

- La praxis ${ }^{13}$ entendida como acción transformadora del mundo, que diferencia a la especie humana de las demás especies del planeta. Es en el quehacer concreto, en la vida cotidiana, donde tiene lugar el compromiso que requiere la sociedad; no se trata de que sea a gran escala o grandes grupos, sino que desde la labor consciente y reflexiva, hombres y mujeres en su diario vivir encuentren y construyan sentidos de vida en el que puedan realizarse plenamente.

De otra parte, es indudable que la diferencia en la posición y la condición de clase de ambos pensadores,

13 Se habla de praxis en tanto acción intencionada y reflexiva. así como las distintas experiencias en sus trayectorias de vida, ubican puntos de partida divergentes, bifurcaciones que aunque disímiles se encuentran en la finalidad teleológica última. Algunas de estas bifurcaciones identificadas son:

- Las ideas de ambos educadores son constitutivas y constituyentes del pensamiento crítico latinoamericano, cuya primera bifurcación se encuentra en la perspectiva teórica asumida para el análisis de la realidad sociopolítica. Freire, claramente con una matriz de corte hegeliano/marxista, explica los procesos de dominación de clase, enfatizando en la educación como instrumento de la clase burguesa para alcanzar sus propósitos económicos y políticos; es decir, ubica la educación como un componente esencial de la superestructura. Fals Borda, por su parte, retoma la ideología del materialismo histórico desde el rol de los intelectuales esbozado por Antonio Gramsci, al centrar su preocupación en el papel que juega el conocimiento científico y los profesionales de las ciencias sociales en las posibilidades concretas de transformación de la realidad. Esta es, hasta cierto punto, una propuesta para ejercer la contrahegemonía, en la medida que la ciencia esté vinculada con el saber popular y con la práctica concreta de los grupos humanos en su vida cotidiana.

- Una segunda bifurcación de esta tradición crítica, que sustentó una concepción filosófica de la praxis, refiere al enfoque desde el que se aborda la educación. Para el sociólogo colombiano la educación es, en sí misma, un proceso de investigación y una práctica de participación en la que los sujetos implicados logran "ver" y "hacer consciente" su propio mundo. Por lo tanto, entiende la educación como experiencia de vida, no solamente desde el marco institucional que tradicionalmente la ha definido. Por su parte, el pedagogo brasileño considera el acto educativo como una estrategia para la concientización y el cambio, desde un enfoque pedagógico que cuestiona a la escuela como sistema educativo formal en el que los procesos de enseñanza/aprendizaje, proyección y servicio a la comunidad están mediados por intereses de clase.

- Como última bifurcación, el pensador colombiano en su afán por articular la teoría con la práctica, insiste en la endogénesis como la posibilidad de creación de interpretación y de intervenciones autóctonas y contextualizadas con las realidades. En tal sentido, otorga primacía a la relación con el ambiente biológico, físico y natural, el cual otorga cierta identidad a los sujetos, en lo que denomina la identidad del trópico, elemento sustancial para destacar los saberes mitológicos y ancestrales que 
predominaron en este lado del continente; de ahí que mitología y racionalidad, razón y corazón, son la cara de una misma moneda que Fals Borda establece para dar cuenta de la multiplicidad cosmogónica, étnica y cultural que caracteriza las sociedades latinoamericanas.

\section{La educación para la concientización: desafíos para los profesionales de las ciencias sociales en las sociedades neoliberales ${ }^{14}$}

Parafraseando a Baugman (2007), las nuevas sociedades "líquidas" enfrentan a las estructuras sociales, a los sujetos y a las políticas, a un mundo de incertidumbre jamás visto. En aquellas sociedades donde las estructuras institucionales han perdido su cimiento, su forma, su capacidad de respuesta y su autonomía, la desesperanza, la incertidumbre, la imposibilidad de prever un futuro se instalan en las mentes de los sujetos. Un mundo donde el conocimiento sobre los hechos que acontecen y la manera de enfrentarlos es insu-

ficiente, donde los marcos

teóricos y pragmáticos que tradicionalmente habían orientado el actuar estatal, individual y de las sociedades carecen de poder en el nuevo marco de relaciones que instaura el mundo global, un mundo en el que los logros se miden por el éxito que creemos que la búsqueda de la conciencia crítica es solo para aquellos a quienes social y personalmente consideramos "desvalidos", porque al parecer nuestra condición profesional nos otorga conciencia crítica...
En tal contexto, ¿qué papel le cabe a los profesionales de las ciencias sociales ${ }^{15}$, por cuya naturaleza ontológica están llamados a cumplir un rol en la transformación social? ¿Cuáles son los desafíos a los cuales se aboca su praxis? ¿Los profesionales de las ciencias sociales reproducen el sistema de dominación hegemónica o, por el contrario, en su quehacer contribuyen a crear un poder contra hegemónico (Vivero, 2010) en donde la liberación y la emancipación sean los pilares de su acción? Sin duda, son múltiples las respuestas a estos interrogantes. No obstante, para efectos de la discusión que se propone instalar en este artículo, se plantean algunos desafíos éticos, cognitivos y prácticos, que consideramos deben enfrentar los profesionales de las ciencias sociales para reavivar y profundizar la experiencia de la educación para la concientización y el cambio social.

\section{Desafíos éticos: el oprimido-opresor}

Existe un consenso generalizado entre académicos, políticos, planificadores de política, movimientos sociales y representantes comunitarios, respecto a las condiciones de pobreza, desigualdad e injusticia social que enfrentan los países latinoamericanos, como resultado de la implementación del modelo neoliberal globalizador impulsado desde la década del setenta del siglo XX. Sin embargo, las políticas sociales y la acción social de los profesionales en los programas y proyectos que operativizan la política, lejos de suscitar una postura crítica que cuestione los intereses y las finalidades que subyacen a estas, paindividual, es el escenario que enfrentan las sociedades líquidas.

Este escenario se acompaña de una ideología determinista basada en la creencia de un destino inmutable que niega la reflexividad y la capacidad de los seres humanos para decidir sobre su vida. Ideología instaurada como dispositivo central de los discursos institucionales, educativos, mediáticos y hegemónicos, como forma esencial de control y dominación de los sujetos.

14 En este aparte, ha sido de especial importancia las contribuciones de Luis Alberto Vivero, a quien agradezco sus apreciaciones, si bien los planteamientos aquí expuestos son de mi exclusiva responsabilidad. recen mantener el ordenamiento social instituido.

15 No se desconoce que los profesionales de las ciencias naturales o exactas, de la salud y de los demás campos del conocimiento deban asumir una postura ética política de compromiso y cambio social; no obstante, se focaliza en los profesionales de las ciencias sociales por cuanto los objetos de estudio y la praxis profesional connota de manera explícita este propósito de intervención. Si bien la IAP y la educación popular ven en la educación -como acto permanente de humanización que trasciende el espacio escolar- la posibilidad para que las personas reflexionen críticamente sobre las condiciones sociohistóricas de vida personal, familiar, comunitaria y social, y desde allí puedan decidir y emprender acciones de cambio, es innegable que la intención educativa de transformación de conductas y comportamientos ha sido un campo más propio de las ciencias sociales y humanas. Si bien adscribo al paradigma de la integralidad, complementariedad y relaciones dialécticas entre los diversos componentes de la vida humana, ubico la reflexión desde la realidad concreta en que se han situado históricamente los campos y las prácticas de conocimiento. 
Una de las razones para que ello ocurra es, como lo señala Freire, que los profesionales también son oprimidos y en esa búsqueda por salir de la opresión, siembran sus esperanzas en la educación como garante de mejores opciones y alternativas de vida - como sin duda lo es-. Cuando han logrado ponerse "por encima" de su clase, gracias al poder que otorga el acceso al conocimiento, olvidan su pasado, su origen, las raíces de su dominación y entonces sale el "opresor" que hay dentro de ellos, reforzando en sus pensamientos, discursos y prácticas la ideología que el sistema impone. 0 se hace parte del sistema como forma para acceder a los medios y los recursos que posibiliten una calidad de vida conforme al estándar de vida predominante, o se mantiene en la oposición, al margen de la práctica de poder y dominación que las instituciones en su conjunto demandan. La disyuntiva no es fácil.

En tal sentido, éticamente es necesario preguntarnos por los principios axiológicos y los intereses a los cuales dirigimos nuestro potencial humano. Desde la concepción de la educación como práctica de libertad, se nos advierte la necesidad de descifrar el dualismo al que nos enfrentamos cuando al querer ser auténticos, terminamos pareciéndonos a lo que nos ha hostigado. El autoritarismo, la creencia en el conocimiento como patrón de verdad única y absoluta, el imperativo por imponerse por sobre los demás, son los valores que la "sociedad líquida", que la sociedad moderna nos muestra como factores de éxito. No obstante, ese camino ha demostrado también las profundas soledades y vacíos existenciales que deja, los cuales, pese a obtener satisfacciones en el plano económico, profesional, familiar, en la esencia misma del ser se sigue aclamando por una humanización, por una búsqueda de conciencia.

La gran tarea humanista e histórica de los oprimidos es liberarse a sí mismos y liberar a los opresores (Freire, 2002, p. 41). El desafío de antes como el de ahora sigue siendo el compromiso decidido - engagement en la perspectiva de Fals Borda-, donde los proyectos individuales tienen sentido en la medida que los otros y las otras, como iguales, pueden acceder a oportunidades y condiciones similares a las nuestras y en donde, pese a las restricciones del contexto, ofrecemos desde nuestra acción cotidiana opciones para que en el encuentro con los demás el respeto, la igualdad y la democracia sean posibles.

\section{Desafíos cognitivos: la búsqueda de transitividad}

Si los profesionales en general y los de las ciencias sociales en particular también son explotados y dominados, ellos también requieren de concientización $\mathrm{y}$, como tal, deben vivir el proceso de transitividad: pasar de una conciencia ingenua a una conciencia crítica que involucra razón y emoción, el compromiso con los otros y con la vida propia.

Si la transitividad crítica corresponde al análisis profundo de los problemas, a la responsabilidad ${ }^{16}$ social y política con el mundo propio y el mundo social, entonces la praxis de los profesionales sociales debe caracterizarse por ser una práctica dialógica donde los campesinos, los pobres, los excluidos, los vulnerados, también cuentan. Una praxis que valora y promueve el saber popular como factor esencial para alcanzar la reflexión y el cambio, que identifica en la historia un elemento potenciador para la acción futura que integra el pasado con el presente, una práctica en donde los profesionales se ponen al servicio de las familias y las comunidades, de sus intereses y necesidades, para tender puentes que sean capaces de visibilizarlos como actores sociales, como seres en el mundo, con poder, con capacidad crítica, y no solo como objetos pasivos, acríticos, objeto de asistencialismo para los fines institucionales y políticos.

El dilema está en que creemos que la búsqueda de la conciencia crítica es solo para aquellos a quienes social y personalmente consideramos "desvalidos", porque al parecer nuestra condición profesional nos otorga conciencia crítica; empero, cuando reflexiva y críticamente miramos nuestro quehacer en el ámbito personal, familiar y social, nos damos cuenta de la fragilidad $-\mathrm{y}$ en algunos casos, inexistencia- con la que participamos en la construcción histórica de la sociedad que vivimos. Asimismo, creemos que la conversación con otros es una relación dialógica, cuando en realidad solo cumplimos con las tareas que demanda el trabajo, para ser lo suficientemente eficientes y eficaces, conforme a la lógica del mercado laboral, cuando lo que realmente importa es ganar el salario que permita mantener y ascender en la escala social que denota el éxito alcanzado. Desde esta lógica, el desafío es avanzar en la consolidación de la democracia sustentada en formas dialógicas emancipadoras.

\section{Desafíos prácticos: liberación conjunta}

Los profesionales sociales, al reconocerse como parte del sistema social de oprimidos y opresores, entienden y asumen la necesidad de la reflexividad, del hacer en una práctica conjunta entre él, la institucionalidad,

16 La responsabilidad se entiende como la capacidad para tomar decisiones en problemas grandes o pequeños con los cuales existe un compromiso. 
las políticas y las personas con quienes desarrolla su acción. La liberación o la emancipación no llega por azar, requiere de una intencionalidad que puede ser generada por las propias condiciones de vida en que se encuentran subsumidas las personas o por la motivación y el impulso que los profesionales, como personas con mayores oportunidades, puedan promover con las familias, los grupos y las organizaciones con las cuales ejercen su labor. En palabras de Freire, la liberación se dará por efectos del trabajo educativo- crítico (2004, p. 56); y, en palabras de Fals Borda en la investigación/participación, se necesitan aspectos fundamentales para que las personas puedan reconocer su capacidad de reflexión, disponer de los instrumentos para enfrentarse al régimen y las clases que los oprimen, comprender las razones históricas que explican sus condiciones materiales de vida y, con ello, las posibilidades concretas para optar y decidir sus modos de actuación en el mundo, conjunta y solidariamente.

Ahora bien, no cabe duda que en sociedades como las nuestras, donde el mercado centrismo es el enclave de la vida personal, familiar, laboral e institucional, estas ideas parecen utópicas. Y en efecto, requerimos de "utopías" que nos permitan recuperar la confianza, que nos permitan creer en la posibilidad de lo imposible, en volver a construir sueños que nos movilizan y que nos alientan. Este ir "contra la marea" no parece, hoy, ser un camino, menos aún cuando las revoluciones experimentadas en nuestras sociedades han pasado a considerarse parte del pasado, como "un fracaso" del que hay que aprender. En contravía, estas revoluciones se reivindican como una alternativa vital para el proyecto de humanización y los profesionales de las ciencias sociales debemos estar atentos para cumplir el papel histórico al que estamos llamados: favorecer la concientización para la acción y el cambio.

\section{Referencias}

Baugman, Z. (2007). Vivir en una época de incertidumbres. Barcelona: Tusquets editores.

Fals Borda, O. (1970a). Algunos problemas prácticos de la sociología de la crisis. Ciencias sociales, ideología y realidad nacional. Buenos Aires: Editorial Tiempo Contemporáneo.

Fals Borda, O. (1970b). Las revoluciones inconclusas en América Latina 1809 - 1968. México D.F.: Siglo XXI Editores.

Fals Borda, 0. (1972). La educación en el proceso revolucionario. Por ahí es la cosa. Ensayos de sociología e historia colombianas. Bogotá: Rosca de Investigación y Acción Social.
Fals Borda, O. (1999). Orígenes universales y retos actuales de la IAP (Investigación Acción Participativa). Análisis Político Núm. 38, pp.71-88.

Fals Borda, O. (2008). Globalización y segunda república. Pensamiento crítico latinoamericano. Cuadernos Clacso (VII - XI), pp. 47 - 61. Publicación de Le Monde Diplomatique. Santiago de Chile: Editorial Aún creemos en los sueños.

Freire, P. (2001). Pedagogía de la indignación. Madrid: Ediciones Morata.

Freire, P. ([1970] 2002a). Pedagogía del oprimido. Buenos Aires: Siglo XXI Editores.

Freire, P. (2002b). Pedagogía de la esperanza. Un reencuentro con la Pedagogía del oprimido. Buenos Aires: Siglo XXI Editores.

Freire, P. (2002c). Pedagogía de la autonomía. Saberes necesarios para la práctica educativa. Buenos Aires: Siglo XXI Editores.

Freire, P. ([1969] 2004). La educación como práctica de libertad. Buenos Aires: Siglo XXI Editores.

Garretón, M.A. et al. (2004). América Latina en el siglo XXI. Hacia una nueva matriz sociopolítica. Santiago de Chile: Lom.

Vivero Arriagada, L. (2010). Cambios sociopolíticos en América Latina: Desafíos para un Trabajo Social crítico latinoamericano. [conferencia]. Tercer encuentro argentino y latinoamericano de Trabajo Social, Universidad de Córdoba, Córdoba. 1, 2 julio. [paper]. 